\title{
The Cost of Hepatitis C Testing Strategies in Primary Care Patients with Abnormal Transaminases
}

\author{
Andrew D. Schreiner, MD, MSCR®, Don C. Rockey, MD, and William P. Moran, MD \\ Department of Medicine, Medical University of South Carolina, Charleston, SC, USA.
}

J Gen Intern Med 35(4):1340-2

DOI: $10.1007 / \mathrm{s} 11606-019-05250-\mathrm{w}$

(c) Society of General Internal Medicine 2019

\section{INTRODUCTION}

Hepatitis $\mathrm{C}$ virus antibody ( $\mathrm{HCV} \mathrm{Ab}$ ) testing of patients born between 1945 and 1965 has dramatically improved $\mathrm{HCV}$ diagnosis in primary care. ${ }^{1} \mathrm{HCV}$ Ab tests are highly sensitive, widely available, and low cost, but require confirmation with HCV RNA when positive. HCV Ab testing is the most cost-effective strategy for screening birth cohort (1945-1965) patients given their anti-HCV prevalence of $3.25 \%$. $^{2}$ Abnormal alanine and aspartate aminotransferases (ALT and AST) are another indication for $\mathrm{HCV}$ testing, but with higher anti-HCV prevalence, the most cost-effective strategy for testing patients with these lab findings is not clear. ${ }^{3}$

To evaluate costs associated with different HCV testing strategies, we modeled (1) reflex testing, a positive HCV Ab immediately followed by confirmatory RNA test without a second blood draw; compared with (2) direct HCV RNA testing for all patients with elevated ALT and $\mathrm{AST}^{4}$ We hypothesized that a direct HCV RNA testing strategy would be more efficient and cost-effective for diagnosing HCV in patients with abnormal transaminases.

\section{METHODS}

Using EHR data from a PCMH, we identified all patients with HCV testing results (Ab or RNA) between 2007 and 2018. Patients were the unit of observation, only included once in the sample, and categorized into 2 groups: (1) 1945-1965 birth cohort and (2) elevated transaminases. Patients were allocated to the elevated transaminase group if they possessed at least one elevated ALT ( $>45 \mathrm{U} / \mathrm{L}$ ) or AST (>34 U/L) result during the study period. We compared testing strategies by cost per patient tested and cost per HCV diagnosis for patients with elevated transaminases and HCV Ab results. Not knowing the RNA status for those patients without follow-up testing, we presumed a similar proportion of positive RNA tests to those with confirmation $(75.7 \%$ in the birth cohort, $80.0 \%$ in the elevated transaminase sample).
We also projected the costs of both strategies for PCMH birth cohort patients and those with elevated transaminases not already tested for $\mathrm{HCV}$. We assumed an anti-HCV prevalence of $3.25 \%$ in the untested birth cohort, and considered prevalence estimates of $12 \%, 8.4 \%$, and $5.5 \%$ in the untested patients with elevated transaminases, based on estimates from previously published data. ${ }^{2,}{ }^{3}$ Median charges from the 2019 Clinical Laboratory Fee Schedule from the Centers for Medicare and Medicaid Services were used to measure costs. ${ }^{5}$ This study was approved by MUSC's IRB.

\section{RESULTS}

Of the 36,841 patients visiting the PCMH between 2007 and $2018,10,973(29.8 \%)$ patients had elevated aminotransferases. Of these, 4873 (44.4\%) had HCV Ab tests and 585 (12.0\% of those tested) had positive results.

Using the HCV testing results previously obtained, and assuming the completion of confirmatory testing, HCV Ab with reflex RNA testing would cost less overall, less per patient tested, and less per HCV diagnosis (Table 1). When the testing strategies were applied to unassessed PCMH groups, HCV Ab with reflex RNA testing led to lower overall cost, cost per patient tested, and cost per diagnosis.

With costs of testing remaining the same, it would require a patient sample prevalence of $53.8 \%$ for direct RNA testing to equal the cost of HCV Ab with reflex RNA (Fig. 1).

\section{DISCUSSION}

HCV Ab testing with reflex RNA was more cost-effective than direct RNA testing for all anti-HCV prevalence projections in PCMH patients with abnormal transaminases. With current cost estimates, direct RNA testing would be more costly in most settings with the possible exceptions of hepatology and needle exchange clinics. This study does not incorporate the psychological harm possibly associated with falsely positive $\mathrm{HCV} \mathrm{Ab}$ tests, a consideration deserving attention in future work. Analyzing the costs of different testing strategies is necessary as $\mathrm{HCV}$ testing expands beyond the birth cohort in primary care.

Published online August 8, 2019 
Table 1 Costs of HCV Testing Strategies by Patient Group and Anti-HCV Prevalence

\begin{tabular}{|c|c|c|c|c|c|}
\hline & \multirow{2}{*}{$\begin{array}{l}\text { Retrospective } \\
\text { Elevated transaminases } \\
(\mathrm{HCV} \text { Ab }+\mathbf{1 2 . 0 \%})\end{array}$} & \multicolumn{4}{|l|}{ Projected } \\
\hline & & \multirow{2}{*}{$\begin{array}{l}\text { Birth cohort (HCV } \\
\text { Ab }+3.25 \%) \\
n=8698\end{array}$} & \multirow{2}{*}{$\begin{array}{l}\text { Elevated transaminases } \\
(\mathrm{HCV} \mathrm{Ab}+12.0 \%) \\
n=6100\end{array}$} & \multirow{2}{*}{$\begin{array}{l}\text { Elevated transaminases } \\
(\mathrm{HCV} \mathrm{Ab}+8.4 \%)^{3} \\
n=6100\end{array}$} & \multirow{2}{*}{$\begin{array}{l}\text { Elevated } \\
\text { transaminases } \\
\text { Trans }(5.5 \%)^{*} \\
n=6100\end{array}$} \\
\hline & $n=4873$ & & & & \\
\hline \multicolumn{6}{|c|}{ HCV Ab with reflex RNA } \\
\hline Total $\operatorname{cost}^{\dagger}$ & $\$ 100,146.68$ & $\$ 151,851.64$ & $\$ 125,352.56$ & $\$ 117,594.09$ & $\$ 111,344.22$ \\
\hline Cost/pt & $\$ 20.55$ & $\$ 17.46$ & $\$ 20.55$ & $\$ 19.28$ & $\$ 18.25$ \\
\hline $\begin{array}{l}\text { Cost/ } \\
\text { diagnosis }\end{array}$ & $\$ 214.45$ & $\$ 709.61 * *$ & $\$ 214.09 * * *$ & $\$ 286.87 * * *$ & $\$ 414.84 * * *$ \\
\hline \multicolumn{6}{|c|}{ Direct RNA testing } \\
\hline Total cost & $\$ 172,163.09$ & $\$ 307,300.34$ & $\$ 215,513.00$ & $\$ 215,513.00$ & $\$ 215,513.00$ \\
\hline $\begin{array}{l}\text { Cost/pt } \\
\text { tested }\end{array}$ & $\$ 35.33$ & $\$ 35.33$ & $\$ 35.33$ & $\$ 35.33$ & $\$ 35.33$ \\
\hline $\begin{array}{l}\text { Cost/ } \\
\text { diagnosis }\end{array}$ & $\$ 368.66$ & $\$ 1436.03$ & $\$ 368.02$ & $\$ 525.74$ & $\$ 802.95$ \\
\hline
\end{tabular}

HCV Ab testing was $\$ 15.85$ (CPT 86803) and HCV RNA testing was $\$ 31.22$ (CPT 87520). Specimen collection tubes cost $\$ 0.46$ and $\$ 4.11$ for the HCV $A b$ and RNA tests respectively (https://www. fishersci.com). Phlebotomy costs were assumed equal. Total cost for HCVAb negative patients was $\$ 16.31$, $\$ 51.64$ for $H C V A b$ positive patients $(A b+R N A)$, and $\$ 35.33$ for patients with direct RNA testing

${ }^{*}$ This prevalence that would be expected in the remaining, untested individuals if we assume an overall anti-HCV prevalence of $8.4 \%$ for all patients with elevated aminotransferases and account for the 585 already testing positive

${ }^{+}$Cost $=16.31 n+35.33($ anti-HCV prevalence $\times n$ )

$\dot{t}=76$ pts with missing RNA. Assuming an additional $0.8 \times 76=60 \mathrm{HCV}$ RNA diagnoses. Total HCV diagnosis now 467

${ }_{* * * *}^{*}$ Assuming $75.7 \%$ of HCV Ab-positive birth cohort patients were HCV RNA positive $(8698 \times .0325 \times 0.757)$

Assuming $80.0 \%$ of HCV Ab-positive patients with HCV RNA testing were HCV RNA positive $(6100 \times$ prevalence $\times 0.8)$

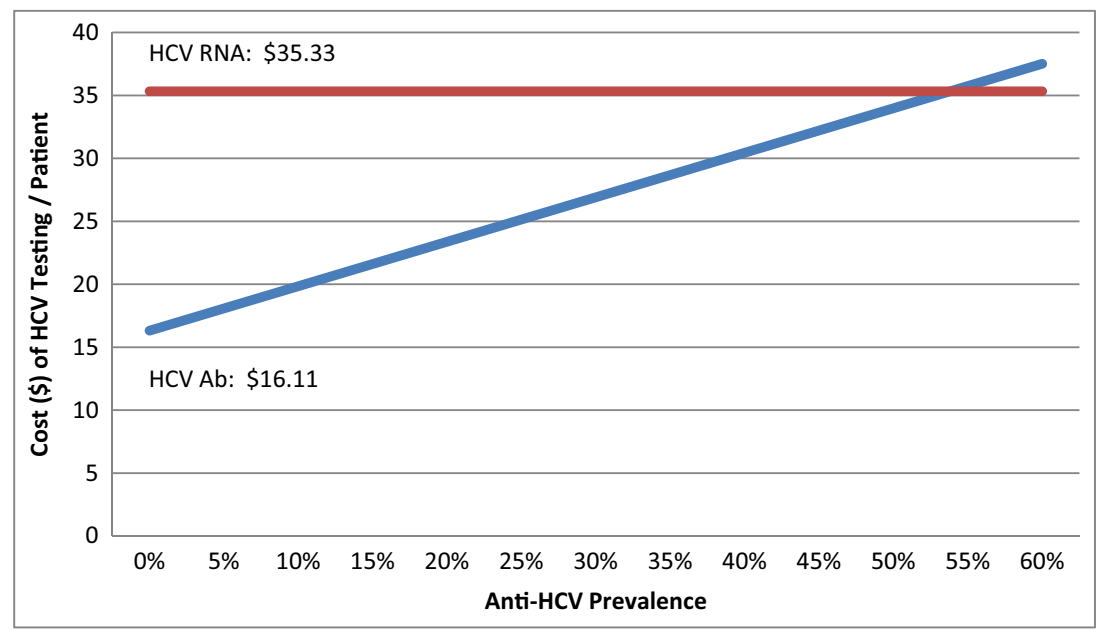

Figure $1 \mathrm{HCV}$ testing cost per patient by anti-HCV prevalence for (1) Ab with reflex RNA and (2) direct RNA strategies. 
Author Contribution. All authors made significant contributions to the completed manuscript.

Corresponding Author: Andrew D. Schreiner, MD, MSCR; Department of Medicine Medical University of South Carolina, Charleston, SC, USA (e-mail: schrein@musc.edu).

Funding This work is financially supported by a K23 Award from the National Institute of Diabetes and Digestive and Kidney Diseases (NIH/NIDDK), 1K23DK118200-O1 (PI: Schreiner).

\section{Compliance with Ethical Standards:}

This study was approved by MUSC's IRB.

Conflict of Interest: The authors declare that they do not have a conflict of interest.

\section{REFERENCES}

1. Barocas JA, Wang J, White LF, et al. Hepatitis C Testing Increased Among Baby Boomers Following The 2012 Change To CDC Testing Recommendations. Health Aff (Millwood). 2017;36(12):2142-2150.

2. Smith BD, Morgan RL, Beckett GA, Falck-Ytter Y, Holtzman D, Ward JW. Hepatitis C virus testing of persons born during 1945-1965: recommendations from the Centers for Disease Control and Prevention. Ann Intern Med. 2012;157(11):817-822.

3. Smith BD, Yartel AK. Comparison of hepatitis C virus testing strategies: birth cohort versus elevated alanine aminotransferase levels. Am J Prev Med. 2014;47(3):233-241.

4. Chapko MK, Dufour DR, Hatia RI, Drobeniuc J, Ward JW, Teo CG. Costeffectiveness of strategies for testing current hepatitis $\mathrm{C}$ virus infection. Hepatology (Baltimore, Md) 2015;62(5):1396-1404.

5. Services CfMM. CY 2019 Q1 Release: Revised for January 2019. 2019.

Publisher's Note Springer Nature remains neutral with regard to jurisdictional claims in published maps and institutional affiliations. 